\title{
Automated Stability Analysis of Soil Slopes
}

\author{
Mikhail Karablin ${ }^{1}$, Dmitry Gurev ${ }^{2}$, and Sergey Prostov ${ }^{2}$ \\ ${ }^{1}$ Siberian branch AO "Vnimi", The Laboratory of Stability of Open-Pit Slopes, 653004 Prokopyevsk, \\ Russian Federation \\ ${ }^{2}$ T.F. Gorbachev Kuzbass State Technical University, Mining Institute, 650000 Kemerovo, Russian \\ Federation
}

\begin{abstract}
Herein there is a description of algorithm of the automated forecast of stability for soil slope structures including input of initial data regarding physical and mechanical properties and geometrical parameters of a structure, building of the most intense sliding face, computation of the slope stability by the polygon of forces method. Developed on algorithm basis, The Stable Slope software package has been implemented in open pit located in the Altai region. There are calculation results of the parameters of the Eastern steady side (slope angle at a given height) depending on the inclination angle of contact of the friable Quaternary deposit with a parent rock. Recommendations can improve work safety under adverse natural and man-made conditions causing formation of unstable water-saturated zones.
\end{abstract}

\section{Introduction}

Provision of slope structures stability at open geo-technology is the most important requirement for modern mining enterprises. Rather difficult task is to prevent landslides of the sides, composed by sand and clay rocks of Quaternary deposits, reaching capacity of $40-50 \mathrm{~m}$. Having sufficient stability at natural humidity, in the moisture-saturated state they sharply reduce strength characteristics that in some cases is capable to cause disturbance of equilibrium of the adjacent rock mass [1].

Theoretical justification for calculation of stability laid by Charles-Augustin de Coulomb, who formulated major principles of the ultimate equilibrium theory and gave its application to engineering problems. Development of ultimate equilibrium calculation methods reflected in works of domestic (V.V. Sokolovskiy, S. S. Golushkevich, N.N. Maslov, R.R Chugayev, G.M. Shahunyants, T.V. Sapozhnikov, and G.L. Fisenko, etc.) and foreign (N.R. Morgenstern, N. Yanbu, E.Spencer, W. Fellenius, A. Bishop, K. Terzaghi) [2-11] scientists. Based on these methods, a number of software has been recently developed providing rapid evaluation of slope structures stability under various engineering-geological conditions. The most renowned of them are as follows: GeoStudio, Slope/W, Galena, Geo5, GeoStab, RS Slide [12-14].

Principle of specialized software operation can be described by one general algorithm. First, a geometric simulation of a slope structure is created analytically - height and slope angle of the structure under estimation are set, according to which software automatically builds a profile, or graphically - a profile is computer-generated in vector editor. The next 
step is to simulate geological conditions, for example, using polygonal objects responsible for a particular geological object with the minimum essential for computation set of physical and mechanical characteristics, or schedule the weighted average characteristics of the layers composing the body of the slope structure. Upon modeling, stability is evaluated by one of the methods, the most common of which are by: Bishop, Morgenstern-Price, Shahunyants, Spencer, and Fellenius, etc. [2-11].

It should be noted that current regulations stipulate stability of slope structures that should be appraised in conformity to certain schemes, taking into account the engineeringgeological conditions of the rock-mass by two methods: algebraic and vector composition of forces. The mentioned methods hereinabove are practically not found in modern software applied for stability calculation [12-14]. In this regard, the authors of the article have developed an algorithm of the analytical calculation of the equilibrium conditions for systems of forces, acting on the elements of the design blocks of the potential sliding surface, corresponding to the recommendations of the Rules for ensuring slope stability for coal mines. The algorithm is implemented in The Stable Slope software package.

The developed Stable Slope software package allows calculation of the boundary parameters for slope of the side flat profile by the limit equilibrium methods - algebraic and vector composition of forces (polygon of forces) for various mining and geological conditions of the adjacent rock-mass: absence of the conformable with slope surface of weakness; presence of flat and steep conformable with slope the natural surfaces of weakening and conformable with slope layers.

\section{Research methods}

There are limit equilibrium method, backward calculation method and analytical simulation method. Method of backward calculations is the most reliable way to determine resistance to shear of rocks in mass as per land survey of natural collapses. The method is based on the fact that before collapse the rock equilibrium in slope is described by the ratio:

$$
\begin{gathered}
\sum_{i=1}^{n} F_{c \partial i}=\sum_{i=1}^{n} F_{m p_{i}}+\sum_{i=1}^{n} F_{c u_{i}} \\
F_{c \partial i}=\gamma_{i} V_{i} \sin \alpha_{i} ; F_{m p_{i}}=\gamma_{i} V_{i} \cos \alpha_{i} \operatorname{tg} \varphi_{i} ; F_{c u_{i}}=C_{i} l_{i},
\end{gathered}
$$

where $\sum_{i=1}^{n} F_{c \partial i}, \sum_{i=1}^{n} F_{m p_{i}}, \sum_{i=1}^{n} F_{c u_{i}}$-sum of shear forces, friction and adhesion force on a point of the most intense sliding surface, respectively; $\gamma_{i}$ - volume weight of soil, $\mathrm{kN} / \mathrm{m}^{3} ; V_{i}$ - volume of design unit, $\mathrm{m}^{3} ; \alpha_{i}$ - sliding surface inclination angle in the middle of design unit, degree; $\varphi_{i}$ - friction angle of soil, degree; $C_{i}$ - cohesion, $\mathrm{kN} / \mathrm{m}^{2} ; l_{i}-$ sliding surface length within design unit with conditionally accepted width of $1 \mathrm{~m}$.

After rock sliding, when adhesion forces on the sliding surface cease to operate, equilibrium of the collapsed masses occurs when shear forces are balanced only by friction forces, i.e. the inequality is fulfilled

$$
\sum_{i=1}^{n} F_{c \partial i} \leq \sum_{i=1}^{n} F_{m p_{i}}
$$


Thus, for each block it is possible to solve two equations with two unknowns -of friction angle $\varphi_{i}$ и cohesion $C_{i}$ of soils.

Below there is an algorithm of soil slope structure stability forecast for the most common design scheme at a flat conformable with a slope of the natural surface of weakness by method of ultimate equilibrium - vector composition of forces. According to this method, equilibrium conditions of the block besides the forces in the equation (1) include the adhesion forces between the side faces of the blocks (Fig. 1).

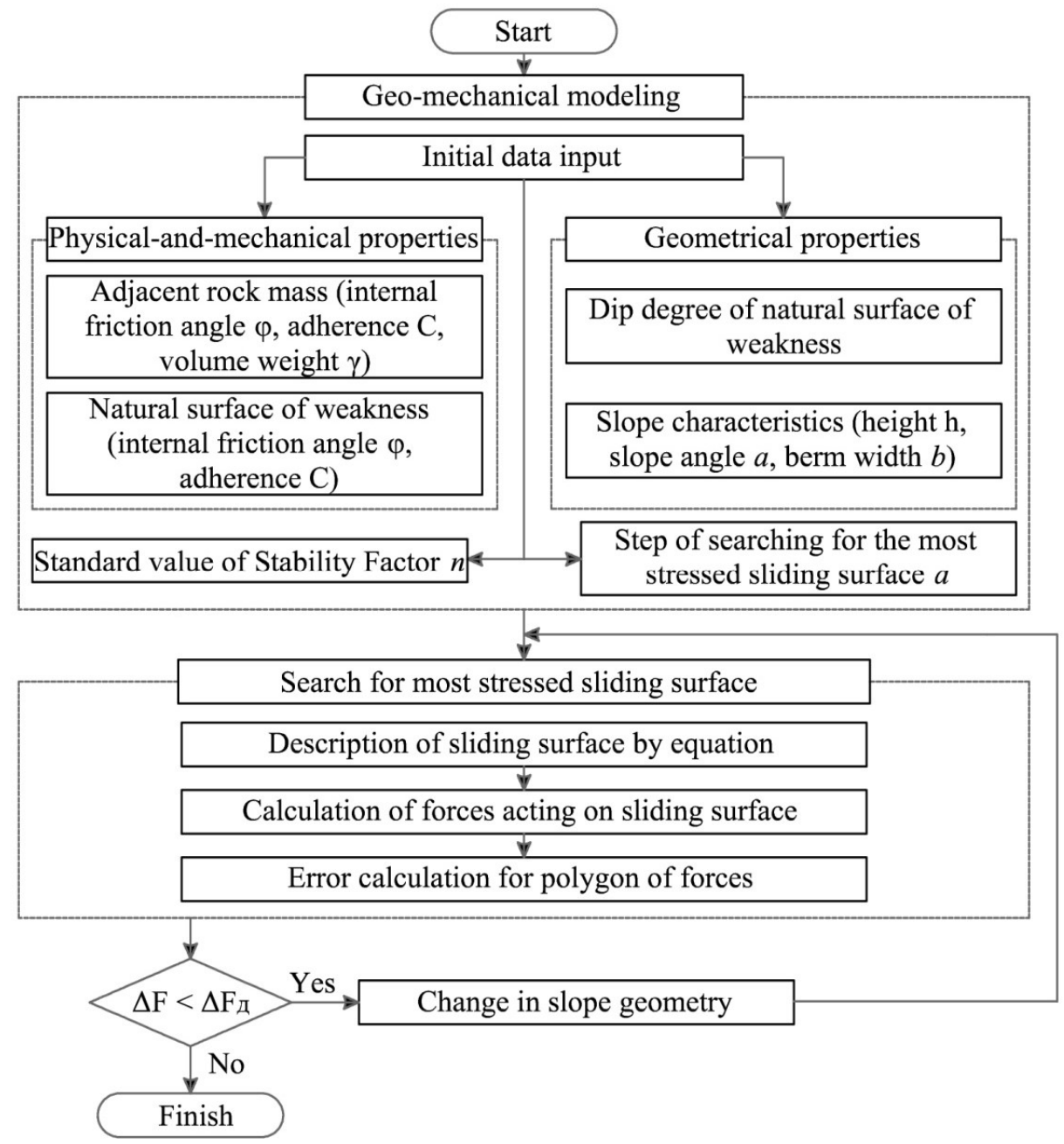

Fig. 1. Algorithm of soil slope structure stability forecast.

The algorithm includes the following main steps:

- $\quad$ setting physical and mechanical properties for rock-mass, geometric parameters, standard value of stability factor (SF) and a step of searching for the most stressed sliding surface,

- $\quad$ building of potential sliding surfaces, computation of forces, and polygon of forces building,

- $\quad$ selection of the most stressed sliding surface. 
The result of the calculation is an error $\Delta F$, which is compared to a permissible value $\Delta F_{\text {д }}$

$$
\Delta F_{c \partial_{i}}=k \sum_{i=1}^{n} \gamma_{i} V i
$$

where $k$ - graphic-analytical calculation error taken in range $0,01-0,02$.

At $\Delta F<0,5 \Delta F_{\partial}$ stability is not provided with a given stability factor. Should adjust the input source data and repeat calculation.

\section{Object of research}

As an object of research the North-Eastern slope in Quaternary deposits of polymetallic ores of the Altai region has been considered. The field is being worked out by open pit method, and as of June 2018, the quarry has been characterized by a side height of about $205 \mathrm{~m}$ with resultant angles of $19-28^{\circ}$. Herewith, the upper part of the slope is composed by Quaternary deposits with a capacity of 20 to $44 \mathrm{~m}$ and has a resulting inclination angle of $10-30^{\circ}$. In the adjacent rock-mass of the open pit there are external rock waste disposal areas: Western and Eastern. The basis of the dumps is a natural relief with a slope towards the open pit. The Central part of the Eastern dump is filled atop the old riverbed. The river is shallow and in summer in its upper part dries up. Waste treatment facilities are located on the Northern side of the open pit. In June 2017 in the cross section area 1 (see Fig. 2) landslide events of the slope were recorded in Quaternary sediments.

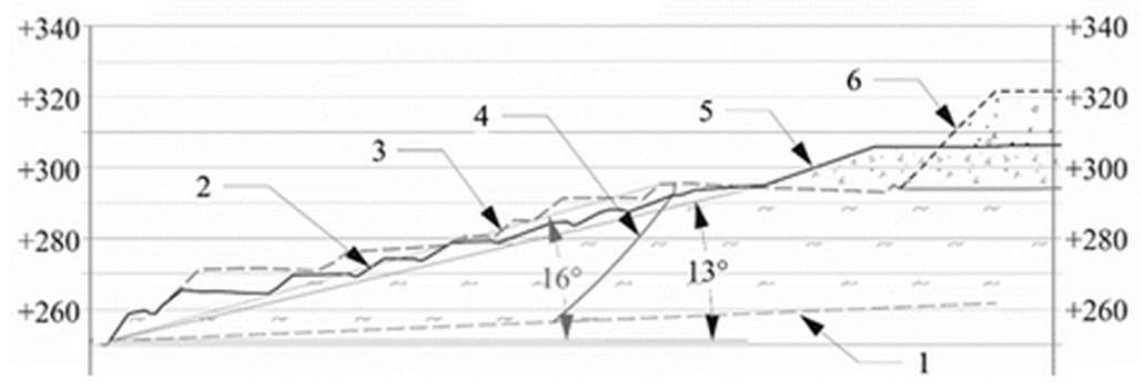

Fig. 2. Section 1 to the retroactive method: 1 - Quaternary deposits - parent rock contact; 2 - slope position after landslide; 3 - slope position before landslide; 4 - most intense sliding surface in adjacent rock-mass, 5 - position of rock waste disposal area after landslide, 6 - position of rock waste disposal area before landslide.

At slope height $44 \mathrm{~m}$ the resulting angle has been $16^{\circ}$, the angle of 'Quaternary deposits - bedrock' contact $-2^{\circ}$. By June 2018 , the slope has been laid out to $13^{\circ}$, involving into the landslide the first layer of the Eastern dump of $27 \mathrm{~m}$ high, located in the adjacent open-pit area at distance $70 \mathrm{~m}$ from the upper edge.

During engineering-and-geological surveys, 4 engineering-and-geological elements (IGE) have been identified: IGE 1 - loamy soil of black and black-brown color; IGE 2 hard-plastic loam of yellowish-brown color with veins of carbonate salts and ferrisol spots; IGE 3 - soft - plastic loam of yellowish-brown color with ferrisol spots; IGE 4 - fluidplastic loam of yellowish - brown color with ferrisol spots.

For engineering-and-geological elements IGE 2 and IGE 3, composing the main part of the geological section, standard value of internal friction angle $\varphi$ varies from $21^{\circ}$ to $24^{\circ}$, volume weight $\gamma$ - from 18.5 to $19.9 \mathrm{kN} / \mathrm{m}^{3}$ at average values of $22.5^{\circ}$, and $19.2 \mathrm{kN} / \mathrm{m}^{3}$, respectively. Standard adherence $\mathrm{C}$ is $12.7 \mathrm{kN} / \mathrm{m}^{2}$. For engineering-and-geological element 
IGE 4 underlying IGE 2 and IGE 3, standard value of internal friction angle $\varphi$, adhesion C and volume weight $\gamma$ are equal to $17^{\circ}, 17.6 \mathrm{kN} / \mathrm{m}^{2}$ and $19.2 \mathrm{kN} / \mathrm{m}^{3}$, respectively. Analysis of the engineering-and-geological survey results figured out that thickness of the Quaternary deposits is composed of loams of the hard-plastic to fluid-plastic consistency from top to bottom. The main cause of the occurred landslides is due to over-moistened rocks of Quaternary deposits. Sources of water are: ancient riverbed, waste treatment facilities, rain and melt water. Due to low filtration properties, water absorbed by the clay rocks does not seep out on the slope, but increases water saturation up to complete swelling and transition into the free-flowing state. Herewith, due to decrease in the strength of rocks, plastic deformations develop, in parallel to the slope edge open mode cracks occur, and gradual subsidence of the breakaway block is observed. In time cracks widen and deepen causing a landslide of rocks.

Parameters of shear resistance on 'Quaternary sediments - bedrock' contract have been determined by the cross-section backward calculations method (Table 1).

Table 1. Physical and mechanical characteristics of Quaternary deposits rocks and shear resistance indicators on the contact of rocks.

\begin{tabular}{|c|c|c|c|}
\hline Name & $\begin{array}{c}\text { Volume weight } \\
\boldsymbol{\gamma}, \mathbf{k N} / \mathbf{m}^{\mathbf{3}}\end{array}$ & $\begin{array}{c}\text { Angle of internal } \\
\text { friction } \boldsymbol{\varphi}, \text { degree }\end{array}$ & $\begin{array}{c}\text { Adhesion } \\
\mathbf{C , ~} \mathbf{~ k N} / \mathbf{m}^{\mathbf{2}}\end{array}$ \\
\hline Quaternary deposits & 19.2 & 17 & 17.6 \\
\hline $\begin{array}{c}\text { Contact "Quaternary deposits - parent } \\
\text { rock" }\end{array}$ & - & 8 & 6.9 \\
\hline
\end{tabular}

Mathematical model of the slope profile (Fig. 3) in The Stable Slope software package has been created by describing its elements (slope side, berm, natural surface of weakness, sliding surface) by algebraic equations (Table 2).

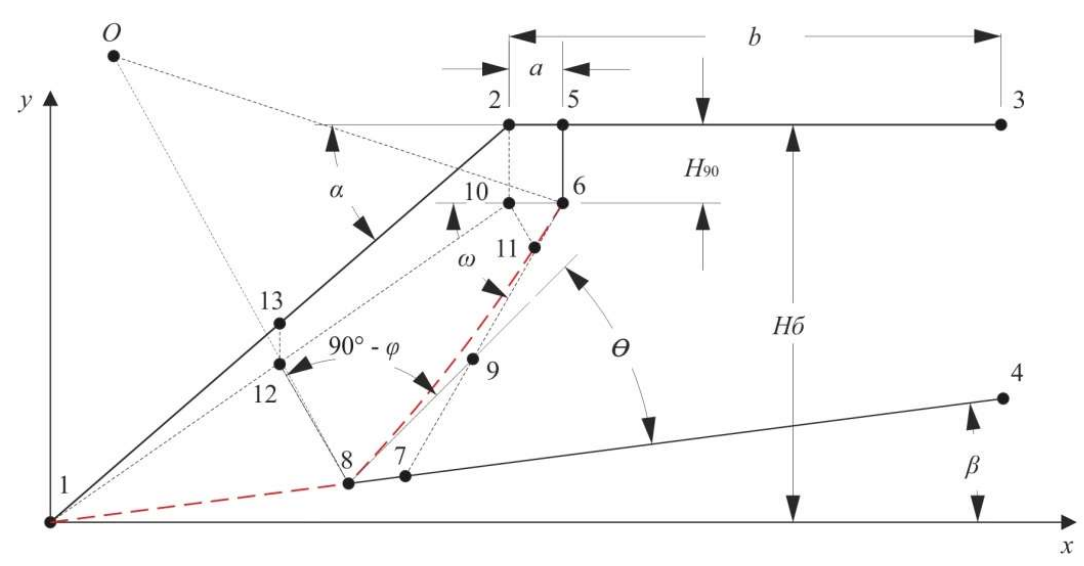

Fig. 3. Mathematical model of a calculated profile of a board.

Table 2. Algebraic equations of slope profile elements.

\begin{tabular}{|c|c|c|}
\hline Board element & Equation & Designations \\
\hline Slope & $y_{i}=x_{i} \operatorname{tg} \alpha_{i}$ & $\alpha$-angle of slope, degree; $H_{\sigma}$ \\
\cline { 1 - 2 } Berm & $y_{i}=H_{\sigma}$ & $\begin{array}{c}\text { slope height, m; } \beta \text { - dip degree natural } \\
\text { surface of weakness, degree. }\end{array}$ \\
\hline $\begin{array}{c}\text { Natural surface of } \\
\text { weakness }\end{array}$ & $y_{i}=x_{i} \operatorname{tg} \beta$ & \\
\hline
\end{tabular}


Computation of the slope parameters has been made according to the scheme, taking into account the gentle conformable with the slope of 'Quaternary deposits - bedrock' contact, and using The Stable Slope software package.

Algebraic equations used for mathematical simulation are limited to the vertices: 1, 2lower and upper sides of slope; 3 - site boundary (berm); 4 - boundary of natural surface of weakness; 5,6 - boundaries of open mode crack; $6,7,8,9$ - points of tangent lines to curved part of sliding surface. Sliding surfaces are built from point 5 along the entire berm width $b$ with a given value of the possible collapse prism a. From the slope platform (berm) a vertical separation platform of is formed. In lower part the sliding surface coincides with the natural surface of weakness (between points 1 and 8), in upper - round cylinder (between points 6 and 8 ) inscribed between tangents at angles $\omega$ and $\theta$. Boundaries of the design blocks are determined by sliding surfaces of the second family: for first block points 10 and 11 , for second block - points 8 and 12 . At exit of the second family sliding surface up to the surface, a vertical separation platform is formed (points $2-10$ and $13-$ 12). Determination of the force vectors acting on the possible collapse prism, as well as the construction of polygon of forces has been also made in analytical form. The calculation result is an error of polygon of forces for given value of stability factor. The closure of polygon of forces characterizes the equilibrium of holding and shear forces.

According to the results of numerous calculations, a dependency graph (Figure 4) of the slope angle to the slope height in Quaternary deposits at different values of 'Quaternary deposits - parent rock' angle contact.

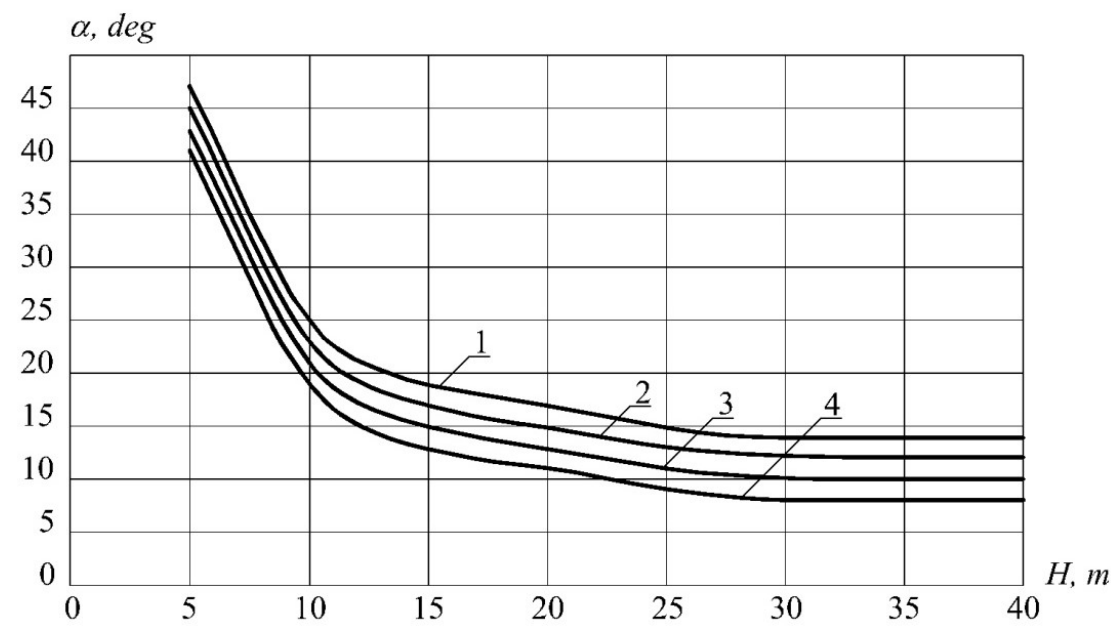

Fig. 4. A plot of the angle of slope of the height of the height of the bead $\mathrm{H}$ in the Quaternary sediments at the angles of incidence "Quaternary sediments - bedrock" consisting of: $1-\beta=0^{\circ} ; 2-\beta$ $=2^{\circ} ; 3-\beta=4^{\circ} ; 4-\beta=6$.

Using the obtained graph, it is possible to quickly determine slope inclination angle (ledge) in Quaternary deposits, providing its stable state at a given height.

\section{Conclusion}

1. Slope structure design procedure is to perform labor-intensive multi-cycle calculations associated with the selection of mining-and-geological conditions and physical-andmechanical properties of the adjacent rock mass of the resulting slope angles for a given height, which will ensure stability. Automated forecast with a help of The Stable Slope software package allows simplifying the design process for stable slopes. 
2. Crucial improvement to forecast accuracy is possible based on transition from flat geological simulations of slopes to volumetric ones with the determination of stability factor of the most hazardous section. The construction of such three-dimensional simulations can be implemented by formalizing data, geological sections and geophysical sounding zones, anomalous on density and moisture saturation.

\section{References}

1. L. Bjerrum, SMFE, 2, 13 (1981)

2. N. Morgenshtern, V. E. Price, Geotechnique, 1, 79 (1965)

3. E. Spencer, Geotechnique, 17, 11 (1967)

4. N. Janbu Proceedings of the European Conference on Stability of Earth Slopes, 3, 43 (1954)

5. J. Jacobczyk, M. Cala, A. Stopkowicz, Studia Geotechnica et Mechanica, 37, 25 (2015)

6. M. Rabie, Comparison study between traditional and finite element methods for slopes under heavy rainfall (HBRC, Chicago, 2014)

7. Yu Zhao, Zhi-Yi Tong, Quing Lu, Mathematical Problems in Engeneering, 71, 2145 (2014)

8. L. Batali, C. Andreea Tong, Quing Lu, Mathematical Problems in Engeneering, 71, $2146(2014)$

9. A. Shivamanth, Athani S. Shivakumar, M.K. Desai, G.R. Dodagoudar, Aquatic Proceedia, 4, 884 (2015)

10. P. Schlotfeldt, D. Elmo, B. Panton, Journal of Rock Mechanics and Geotechnical Engineering, 10, 72 (2018)

11. M. Koleini, J. Rooy, Bull Eng Geol Environ, 71, 691 (2012)

12. M. Digvijay, P. Salunkhe, IJERT, 3, 528 (2017)

13. A. Baltiyeva, A. Altayeva, S. Sedina, L. Shamganova, K. Tulebayev, SGEM, 2, 525 (2016)

14.E. Garmondyu, J. Crusoe, C. Qing-Xiang, S. Ji-Sen, H. Liu, J. Barvor, Int. J. Min. \& Geo-Eng, 50, 1 (2016) 